\title{
Modification of Carbon Paste Electrode with Ag Nanoparticle for Voltammetric Determination of Phenol
}

\author{
Tri Sulistyorini ${ }^{1}$, Henry Setiyanto ${ }^{2}$, Muhammad Ali Zulfikar ${ }^{3}$, \\ Vienna Saraswaty ${ }^{4}$, Nandang Mufti ${ }^{5}$ \\ $\left\{\right.$ henry@ chem.itb.ac.id $\left.{ }^{2}\right\}$ \\ Analytical Chemistry Research Group, Institut Teknologi Bandung ${ }^{1,2,3}$
}

\begin{abstract}
Phenol is an aromatic derivative of hydrocarbons from coal which used as a base for making plastic bottles, cans of packaged food, and pesticides. However, this compound is emerging as a pollutant in the environment. This work, the carbon paste electrode based on Ag nanoparticle was developed for the detection of phenol. Carbon paste electrode modified Ag nanoparticles which were previously synthesized first and then mixed with graphite and paraffin. The best composition of CPE-nAg is 5:70:25 for Ag nanoparticles, graphite, and paraffin, respectively. After measurement using CPE-nAg, it is necessary to remove phenol on the electrode surface with 6 cycles. Measurement was carried out using square wave voltammetry techniques range with $0 \mathrm{~V}$ to $1.2 \mathrm{~V}$, a frequency of $10 \mathrm{~Hz}$, and a scan rate of $75 \mathrm{mV} / \mathrm{s}$. The result showed the presence of an oxidation peak of phenol is $0.475 \mathrm{~V}$ in $1 \mathrm{M}$ of sodium hydroxide solution.
\end{abstract}

Keywords: CPE, Ag nanoparticles, Voltammetric, Phenol

\section{Introduction}

Phenols are pollutants in industrial waste that have low degradability and in low concentrations, phenols can cause toxicity and bioaccumulation problems. Phenolic compounds can be found in water that is the result of waste from the food industry and the chemical industry such as in the production of resins, pesticides, and oil refineries [1]. Based on the Minister of Health Decree No.907/MENKES/SK/VII/2002, the maximum concentration of phenol that declared safe in the water for aquatic ecosystem life is $0.5-1.0 \mathrm{mg} / \mathrm{L}$ [2]. A large amount of phenol in industrial fields cause phenol easily found in water. This has quite an impact on the environment because phenols are also known to be very reactive to human body tissues if absorbed through contact with the skin, breathing, and digestion. Contact with phenols can cause irritation, dermatitis, and burn [3].

Several studies have explained how to detect phenols accurately and sensitively such as adsorption using eggshell [4], HPLC-UV [5], UV-VIS spectrophotometers [6], and highperformance liquid chromatography [7]. However, these techniques need expensive instrumentation, so we need another analytical method for the determination of phenols in the sample. One method that can be used is electrochemistry which has several advantages such as high sensitivity and selectivity, simple modification, and economical [8],[9],[10],[11],[12]. In voltammetric techniques, usually using electrodes that the reactivity of an electrode depends on 
the composition of its constituent materials, so that optimization of the composition is needed to obtain a good electrode. The electrodes used are carbon paste electrodes (CPE) which have several advantages such as easy modification processes, renewable surfaces, and economical. Carbon paste electrodes modified by adding a certain substance can detect samples in very small levels so high selectivity can be obtained [13]. The use of nanomaterials in CPE has been widely used because it can increase sensitivity and selectivity in electrochemical. Nanomaterials that commonly used are nickel, gold, and silver.

Silver nanoparticles (nAg) are widely used because easily obtained, inexpensive, and produce good catalytic properties [14]. Synthesis of Ag nanoparticles which is widely used is by reducing silver ions in various stabilizers such as surfactants and polymers [15],[16]. In this study, the synthesis of Ag nanoparticles was carried out using polyvinylpyrrolidone (PVP) which is quite interesting because of its excellent physical and chemical properties as a coating [17]. PVP is a biocompatible polymer that is one of the water-soluble polymers and PVP works as a stabilizer of metal nanoparticles but also has an impact on the control level of the reduction of silver ions and aggregation process of the silver atom [18].

In this paper, phenol measurements were carried out by carbon paste modified $\mathrm{Ag}$ nanoparticles (CPE-nAg). The parameters studied were the optimum composition of $\mathrm{Ag}$ nanoparticles, the number of phenol removal cycles, and anodic peak analysis of phenols.

\section{Experimental}

\subsection{Reagents, Solution, and Samples}

The chemicals used in this study were graphite powder, paraffin oil, silver nitrate/ $\mathrm{AgNO}_{3}$, phenol/ $\mathrm{C}_{6} \mathrm{H}_{5} \mathrm{OH}$, potassium hexacyanoferrate $(\mathrm{II}) / \mathrm{K}_{4}\left[\mathrm{Fe}(\mathrm{CN})_{6}\right]$, potassium hexacyanoferrate (III) $/ \mathrm{K}_{3}\left[\mathrm{Fe}(\mathrm{CN})_{6}\right]$, sodium borohydride $/ \mathrm{NaBH}_{4}$, sodium chloride $/ \mathrm{NaCl}$, L-glutamic acid, Polyvynilpyrrolidone/PVP, sodium hydrogen phosphate $/ \mathrm{Na}_{2} \mathrm{HPO}_{4}$, sodium hydroxide/ $\mathrm{NaOH}$, and sodium dihydrogen phosphate $/ \mathrm{NaH}_{2} \mathrm{PO}_{4} \cdot \mathrm{H}_{2} \mathrm{O}$. These reagents are available in the chemistry department laboratory. Electrolyte solution used is phosphate buffers for removing phenol from the electrode surface while sodium hydroxide was used as the supporting electrolyte to dissolve phenol.

\subsection{Preparation of Reference Electrode}

In the making reference electrode $(\mathrm{Ag} / \mathrm{AgCl}$ electrode), the first silver wire is sanded then electrolyzed with $0.1 \mathrm{M} \mathrm{NaCl}$ solution at the potential of $0.223 \mathrm{~V}$ for 2 minutes until a black $\mathrm{AgCl}$ layer will be formed on the surface of the $\mathrm{Ag}$ wire. In this process, $\mathrm{Ag}$ wire functions as a working electrode and $\mathrm{Pt}$ wire has functioned as a reference electrode. Furthermore, the electrolyzed $\mathrm{Ag}$ wire is inserted into the electrode body which has been filled with $3 \mathrm{M} \mathrm{NaCl}$ solution and characterized in a $0.01 \mathrm{M} \mathrm{K}_{3}\left[\mathrm{Fe}(\mathrm{CN})_{6}\right]$ and $\mathrm{K}_{4}\left[\mathrm{Fe}(\mathrm{CN})_{6}\right]$ solution in $0,1 \mathrm{M} \mathrm{NaCl}$. Characterization was performed using the cyclic voltammetry $(\mathrm{CV})$ method in the potential range of $-200 \mathrm{mV}$ to $800 \mathrm{mV}$ with a scan rate of $100 \mathrm{mV} / \mathrm{s}$ for 1 cycle. The characterization results compared with BAS commercial reference electrode. 


\subsection{Synthesis of Ag Nanoparticles}

Ag nanoparticles were synthesized with polyvinylpyrrolidone (PVP). Synthesis of nAg was carried out by dissolving 0.025 grams of $\mathrm{AgNO}_{3}$ in $500 \mu \mathrm{L}$ distilled water. Then this solution is dropped into $20 \mathrm{~mL} \mathrm{PVP}$ and also added with a $5 \mathrm{~mL} \mathrm{NaBH}_{4}$ solution. The mixture of this solution is stirred for 1 hour. After one hour, a dark brown solution will be produced which indicates the formation of the Ag nanoparticles. This solution kept in room temperature and stable in 90 days.

\subsection{Preparation of Carbon Paste Electrode Modified Ag Nanoparticles}

Carbon paste electrode modified $\mathrm{Ag}$ nanoparticles $(\mathrm{nAg})$ was prepared by adding graphite, paraffin oil, and $\mathrm{Ag}$ nanoparticles. The amount of $\mathrm{Ag}$ nanoparticles given was varied to 5, 15, 25 , and $35 \%$. From the measurement results, the maximum yield is obtained when $\mathrm{nAg}$ are in the amount of 5\% with a ratio of 70: 25: $5(\% \mathrm{w} / \mathrm{w})$ for graphite, paraffin oil, and $\mathrm{nAg}$, respectively. Then the mixture is heated until $70^{\circ} \mathrm{C}$ to form a homogeneous paste. Then the paste is inserted into the body of the electrode that containing copper wire while being pressed until it is solid. The final step is rubbing the surface of the carbon paste on a clean paper.

\section{Results and Discussion}

\subsection{Characterization of Reference Electrodes}

In this study, phenol measurements were carried out using 3 electrodes that are $\mathrm{Ag} / \mathrm{AgCl}$ electrode as a reference electrode, CPE-nAg as a working electrode, and Pt wire as an auxiliary electrode. $\mathrm{Ag} / \mathrm{AgCl}$ reference electrode was characterized by cyclic voltammetry method in the potential range of $-200 \mathrm{~V}$ to $800 \mathrm{~V}$ for 1 cycle using the mixture of $\mathrm{K} 4 \mathrm{Fe}(\mathrm{CN}) 6$ and $\mathrm{K} 3 \mathrm{Fe}(\mathrm{CN}) 6$ in $0,1 \mathrm{M} \mathrm{NaCl}$ solution. Furthermore, the results of the $\mathrm{Ag} / \mathrm{AgCl}$ electrode's characterization compared with the BAS electrodes. The results of the characterization of these electrodes must resemble (coincide) in order to show the same quality. This is important to ensure there are no errors in the measurements that can be caused due to the poor quality of the comparison electrodes. The cyclic voltammogram of these electrodes is presented in Figure 1. 


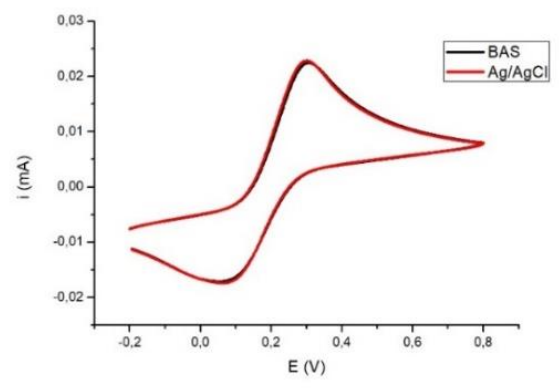

Fig. 1. Cyclic voltammogram of $\mathrm{Ag} / \mathrm{AgCl}$ electrode and $\mathrm{BAS}$ electrode in solution mixture of $\mathrm{K} 4 \mathrm{Fe}(\mathrm{CN}) 6$ and $\mathrm{K} 3 \mathrm{Fe}(\mathrm{CN}) 6$ in $0,1 \mathrm{M} \mathrm{NaCl}$ solution.

Based on the voltammogram in Figure 1, it can be seen that the $\mathrm{Ag} / \mathrm{AgCl}$ electrode and BAS electrode are very coinciding. Anodic and cathodic peak current values resulting from $\mathrm{Ag} / \mathrm{AgCl}$ electrode characterization are shown in Table 1.

Table 1. Characteristic value of $\mathrm{Ag} / \mathrm{AgCl}$ and BAS electrode.

\begin{tabular}{cccccc}
\hline Electrode & $\mathrm{Ipa}(\mu \mathrm{A})$ & $\mathrm{Ipc}(\mu \mathrm{A})$ & $\mathrm{Epa}(\mathrm{V})$ & $\mathrm{Epc}(\mathrm{V})$ & $\mathrm{E}^{0}(\mathrm{~V})$ \\
\hline BAS & 22.24 & 17.19 & 0.290 & 0.089 & 0.1895 \\
$\mathrm{Ag} / \mathrm{AgCl}$ & 22.67 & 17.58 & 0.285 & 0.093 & 0.1890 \\
\hline
\end{tabular}

\subsection{Determination of Composition Carbon Paste Electrode Modified Ag Nanoparticles}

Variation of Ag nanoparticle composition needs to be done in order for the best composition of $\mathrm{Ag}$ nanoparticles is known so the sensitivity will be getting better. Variation composition of $\mathrm{Ag}$ nanoparticles is done by making 4 variants with the ratio of graphite, paraffin, and $\mathrm{Ag}$ nanoparticles respectively (70:25:5), (70:20:10), (70:15:15) and (70:10:20). Measurements were made using a square wave voltammetry technique with a scan rate of $75 \mathrm{mV} / \mathrm{s}$, frequency of $10 \mathrm{~Hz}$, in the potential range of $0 \mathrm{~V}$ to $1,4 \mathrm{~V}$ in a $10 \mathrm{mM}$ phenol solution. Results of measurement of $10 \mathrm{mM}$ phenol solution using CPE-nAg with various composition comparisons are shown in Figure 2. 


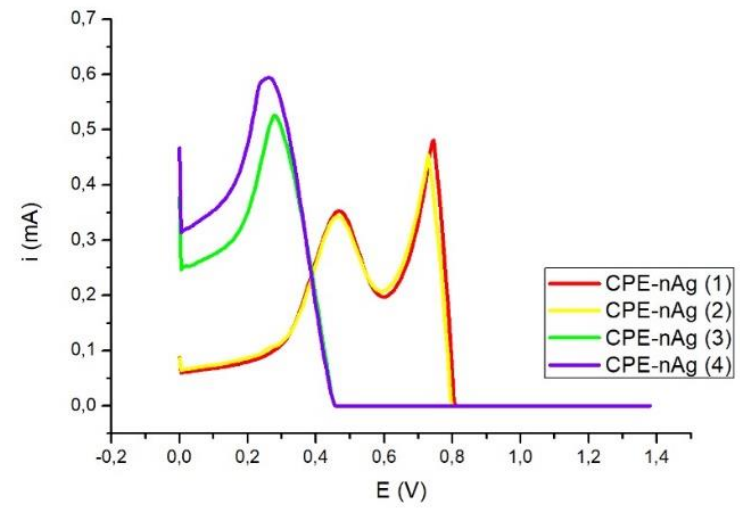

Fig. 2. Effect of variations in the composition of Ag nanoparticles on anodic peak current of $10 \mathrm{mM}$ phenol in $1 \mathrm{M} \mathrm{NaOH}$ solution using SWV techniques.

Based on Figure 2, measurements using CPE-nAg 1 give a higher current compared to CPE-nAg 2 which is $0.3526 \mathrm{~mA}$ with a potential value of $0,465 \mathrm{~V}$. But on measurements using CPE-nAg 3 and CPE-nAg 4, the potential given becomes more negative compared to the supposed value of $0.280 \mathrm{~V}$. The existence of this potential value shift, can be caused by the influence of the composition of $\mathrm{Ag}$ nanoparticles given in the carbon paste mixture. In the measurement of phenol using CPE-nAg 3 and CPE-nAg 4 the composition of each electrode was (70:15:15) and (70:10:20) where the amount of $\mathrm{Ag}$ nanoparticles used were 0.075 grams and 0.100 grams. The amount of $\mathrm{Ag}$ nanoparticles is more than the liquid paraffin used, causing the paste to be less homogeneous. The measured phenolic anodic peak current value is shown in Table 2.

Table 2. Measurement anodic peak current of $10 \mathrm{mM}$ phenol in $1 \mathrm{M} \mathrm{NaOH}$ using CPE-nAg with various comparisons.

\begin{tabular}{cccccc}
\hline $\mathrm{nAg}$ & Graphite $(\mathrm{g})$ & Paraffin oil $(\mathrm{g})$ & $\begin{array}{c}\text { Ag Nanoparticles } \\
(\mathrm{g})\end{array}$ & $\mathrm{i}(\mathrm{mA})$ & $\mathrm{E}(\mathrm{V})$ \\
\hline 1 & 0.35 & 0.125 & 0.025 & 0.3526 & 0.465 \\
2 & 0.35 & 0.100 & 0.050 & 0.3422 & 0.480 \\
3 & 0.35 & 0.075 & 0.075 & 0.5259 & 0.280 \\
4 & 0.35 & 0.050 & 0.100 & 0.5880 & 0.275 \\
\hline
\end{tabular}

After knowing the right electrode composition, it is necessary to remove the analyte (phenol) from the electrode surface. Phenol removal is carried out using cyclic voltammetry in the potential range of $0 \mathrm{~V}$ to $1,4 \mathrm{~V}$ with a scan rate of $100 \mathrm{mV} / \mathrm{s}$. After phenol removal, CPE$\mathrm{nAg}$ was measured in $10 \mathrm{mM}$ phenol solution using the SWV technique with a scan rate of 75 $\mathrm{mV} / \mathrm{s}$, frequency of $10 \mathrm{~Hz}$, in the potential range of $0 \mathrm{~V}$ to $1,4 \mathrm{~V}$. Effect of the number of phenol removal cycles is shown in Figure 3. 


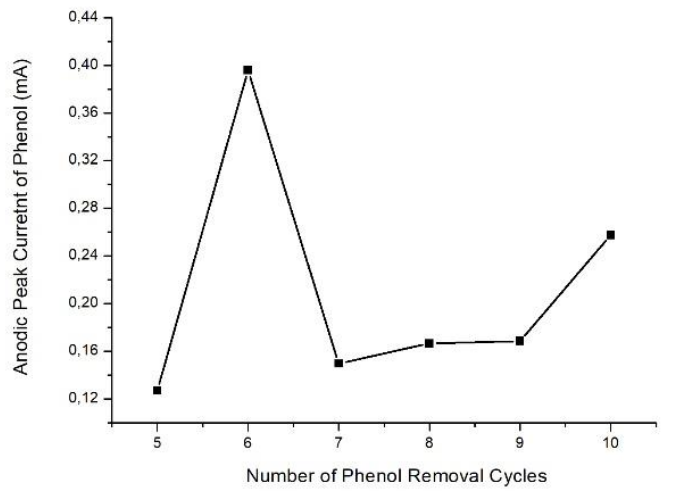

Fig. 3. Effect of the number of phenol removal cycles on the phenolic anodic peak current in $10 \mathrm{mM}$ phenol solution.

Figure 3 shows that the removal of phenol from CPE-nAg with 6 cycles gives the highest anodic peak current in $0.3960 \mathrm{~mA}$ with a potential value of $0.470 \mathrm{~V}$.

\subsection{Evaluation of Phenol Anodic Peak Current}

Evaluation peak of phenol is done by comparing the peak of phenol using unmodified CPE and CPE-nAg. Measurements were made using square wave voltammetry techniques in the potential range of $0 \mathrm{~V}$ to $1.4 \mathrm{~V}$ with a scan rate of $75 \mathrm{mV} / \mathrm{s}$ in a $10 \mathrm{mM}$ phenol solution. The results of the measurement of two electrodes are compared to determine the good electrode performance. Square wave voltammograms in measurements of phenol peak by different electrodes are shown in Figure 4.

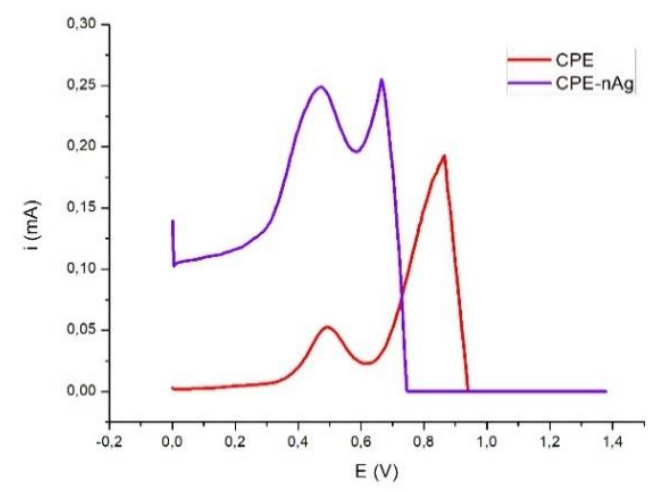

Fig. 4. Voltammogram measurement of $10 \mathrm{mM}$ phenol in $1 \mathrm{M} \mathrm{NaOH}$ solution using unmodified $\mathrm{CPE}$ and CPE-nAg.

Based on Figure 4, seen that the phenolic anodic peak currents measured using CPE-nAg are higher than unmodified CPE. CPE gives a very small current because the electron transfer 
kinetics of CPE is slow due to the buildup of oxidation products that pollute the surface of the working electrode. While CPE-nAg provides higher anodic peak currents compared to others due to the presence of $\mathrm{Ag}$ nanoparticles in carbon paste mixture used so it can increase the interactions with phenols. A comparison of the phenolic anodic peak current values is shown in Table 3.

Table 3. Comparison of anodic peak current value and potential oxidation of phenol $10 \mathrm{mM}$ using different electrodes.

\begin{tabular}{ccc}
\hline Electrode & $\mathrm{i}(\mathrm{mA})$ & $\mathrm{E}(\mathrm{V})$ \\
\hline CPE & 0.0524 & 0.490 \\
CPE-nAg & 0.2481 & 0.475 \\
\hline
\end{tabular}

\section{Conclusions}

Modification of carbon paste electrodes using Ag nanoparticles is successfully carried out using a square wave voltammetry technique by giving a high current value compared to unmodified CPE. The best composition of CPE-nAg is 70:25:5 (\%w/w) for graphite, paraffin, and $\mathrm{Ag}$ nanoparticles. Measurements of phenol were made using square wave voltammetry techniques with a scan rate of $75 \mathrm{mV} / \mathrm{s}$ in the potential range of $0 \mathrm{~V}-1.4 \mathrm{~V}$ in a $10 \mathrm{mM}$ phenol solution. The result showed a phenol oxidation peak in $0.475 \mathrm{~V}$ in $1 \mathrm{M}$ of sodium hydroxide solution.

Acknowledgments. The authors are very grateful to Hibah PTUPT 2019 Ristekdikti for their financial support for this research study.

\section{References}

[1] Nady, H., El-Rabiei, M.M., and Abd El-Hafez, G.M.: Electrochemical oxidation behavior of some hazardous phenolic compounds in acidic solution. Egyptian Journal of Petroleum. pp. 1-10 (2016)

[2] Suprasetyo, A. and Setiarso, P.: Pembuatan elektroda pasta karbon termodifikasi zeolit untuk analisis fenol secara cyclic stripping voltammetry. UNESA Journal of Chemistry. Vol. 5 (3), pp. 86-93 (2016)

[3] Lin, T.M., Lee, S.S., Lai, C.S., and Lin, S.D.: Phenol Burn. Burns. Vol. 32, pp. 517-521 (2006)

[4] Kashi, G.: On the analysis of phenol removal from drinking water by batch reactor using powdered eggshell. Bioscience Biotechnology Research Communication. Vol 10 (2), pp. 287-296 (2017)

[5] Higashi, Y.: Simple HPLC-UV analysis of phenol and its related compounds in tap water after precolumn derivatization with 4-nitrobenzoyl chloride. Journal of Analytical Sciences, Methods, and Instrumentation. Vol. 7, pp. 18-28 (2017)

[6] Yadav, D.K. and Harjit, J.: Determination of phenol compounds in wastewater by using a compelling agent: N-phenyl-benzoic-hydroxamic acid. Journal of Applied Chemistry. Vol. 4, pp. 6-12 (2014)

[7] Yang, S., Arasu, M.V., Chun, J., Jang, Y., Lee, Y., Kim, I. H., Lee, K., Hong, S., and Kim, S.: Identification and determination of phenolic compounds in rapeseed meals (Brassica napus L.). Journal of Agricultural Chemistry and Environment. Vol. 4, pp. 14-23 (2015) 
[8] Bakker, E.: Electrochemical sensors. Anal. Chem. Vol. 76, pp. 3285-3298 (2004)

[9] Ianesko, F., Alves de Lima, E., Antoniazzi, C., Santana, E.R., Piovesan, J.V., Spinelli, A., Galli, A., and Guimaraes de Castro, E.: Simultaneous electrochemical determination of hydroquinone and bisphenol a using a carbon paste electrode modified with silver nanoparticles. Electroanalysis.Vol. 30, pp. 1-11 (2018)

[10] Setiyanto, H., Saraswaty, V., Hertadi, R. and Buchari, B.: Determination of the Reactivity of the Anti-cancer Nitrogen Mustard-Mechlorethamine : A Cyclic Voltammetric Investigation. Analytical and Bioanalytical Electrochemistry. Vol. 7(6), pp. 657-665 (2015)

[11] Setiyanto, H., Saraswaty, V., Hertadi, R., Noviandri, I. and Buchari, B.: Chemical Reactivity of Chlorambucil in Organic Solvents: Influence of 4-Chloro Butyronitrile Nucleophile to Voltammogram Profiles. International Journal of Electrochemical Science. Vol. 6, pp. 2090-2100 (2011)

[12] Setiyanto, H., Saraswaty, V., Hertadi, R., Noviandri, I. and Buchari, B.: Cyclic Voltammetric Study of Chlorambucil in The Presence of 4-Chloro Butyronitrile in Aqueous Solution. International Journal of ChemTech Research. Vol. 3(4), pp. 1986-1992 (2011)

[13] Apriliani, R.: Studi penggunaan kurkumin sebagai modifier elektroda pasta karbon untuk analisis timbal (II) secara stripping voltammetry. Essay. Universitas Sebelas Maret. Surakarta, (2009)

[14] Goulart, L.A., Goncalves, R., Correa, A.A., Perelra, E.C., and Mascaro, L.H.: Synergic effect of silver nanoparticles and carbon nanotubes on the simultaneous voltammetric determination of hydroquinone, catechol, bisphenol A, and phenol. Microchimica Acta. pp. 1-9. (2017)

[15] Panacek, A., Kvitek, L., Prucek, R., Kolar, M., Vecerova, R., Pizurova, N., Sharma, V.K., Nevecna, T., and Zboril, R.: Silver colloid nanoparticles : synthesis, characterization, and their antibacterial activity. J Phys Chem B. Vol. 33, pp. 16248-16253 (2006)

[16] De Matteis, V., Cascione, M., and Toma, C.C.: Silver nanoparticles : Synthetic routes, in vitro toxicity and theranostic applications for cancer disease. Nanomaterials. Vol.8, pp 1-23. (2018)

[17] Bryaskova, R., Pencheva, D., Nikolov, S., and Kantardjiev, T.: Synthesis and comparative study on the antimicrobial activity of hybrid materials based on silver nanoparticles (AgNps) stabilized by polyvinylpyrrolidone (PVP). J Chem Biol. Vol. 4, pp. 185-191 (2011)

[18] Carotenuto, G.: Synthesis and characterization of poly(N-vinylpyrrolidone) filled by monodispersed silver clusters with controlled size. Applied Organometallic Chemistry. Willey Online Library 15: 344 (2001) 